\title{
A NEW UV OXIDATION SETUP FOR SMALL RADIOCARBON SAMPLES IN SOLUTION
}

\author{
Peter Steier ${ }^{1,2}$ - Christina Fasching ${ }^{3}$ Klaus Mair ${ }^{1}$ Jakob Liebl ${ }^{1,4} \bullet$ Tom Battin $^{3}$ • Alfred Priller ${ }^{1}$ \\ Robin Golser ${ }^{1}$
}

\begin{abstract}
The requirements of extracting minute amounts of organic carbon in solution with high yield and minimum background are a prerequisite for radiocarbon dating of microgram amounts of carbon. Samples for biomedical or environmental research often arrive at the accelerator mass spectrometry (AMS) lab as concentrates dissolved in $1 \mathrm{~mL}$ of water or less. We have developed a new extraction method based on photo-oxidation by ultraviolet (UV) light. The solution is transferred into UV-transparent quartz vials with a head volume of pure oxygen and UV from low-pressure mercury discharge lamps is applied. To exclude the introduction of carbon background, we avoid any additional oxidizing agents. Under these conditions, only the $185 \mathrm{~nm}$ line is considered effective. To characterize the yield and the background, we have investigated artificial samples prepared from different materials. The setup developed allows parallel oxidation of 9 samples within typically $2 \mathrm{hr}$, connected directly to our graphitization setup for extremely small samples. The method was applied successfully for a study on dissolved organic carbon (DOC) in ice from 26 Austrian glaciers. A special advantage of the UV oxidation method in this case was that phosphoric acid could be used to remove carbonates, while its low vapor pressure prevented complete lyophilization. We see the most promising field of application in biomed research and compound-specific analysis.
\end{abstract}

\section{INTRODUCTION}

For the various sample materials encountered in a radiocarbon accelerator mass spectrometry (AMS) laboratory, a vast range of different sample preparation methods was developed. All existing protocols involve production of $\mathrm{CO}_{2}$, and organic carbon is converted to $\mathrm{CO}_{2}$ by oxidation. The oxidation is usually done by heating the sample to high temperature in the presence of oxygen (or a material releasing oxygen at high temperatures). Compared to wet oxidation, high-temperature combustion makes sure complete digestion of carbon, and imposes a smaller risk of contamination by reagents added. However, combustion is not always possible. We have developed a procedure based on ultraviolet light, which has advantageous properties for certain types of samples, especially for small samples of organic carbon in (aqueous) solution of relatively small volumes $(<1 \mathrm{~mL})$.

The main motivation to start the method development was a joint project between the Department of Limnology and the VERA facility. In a geobiological study to understand the role of glaciers in the global carbon cycle (Singer et al. 2012), samples from 26 glaciers in the European Alps were collected and the molecular composition and bioavailability of the dissolved organic carbon (DOM) in the meltwater was assessed. The contribution of VERA was to determine ${ }^{14} \mathrm{C}$ contents. Complete chemical yield was not mandatory for this application, since only correlations between the measured ${ }^{14} \mathrm{C}$ contents and other biogeochemical parameters were used in the interpretation. The samples available for this purpose were aliquots of DOM concentrates corresponding to several $\mathrm{kg}$ of ice, melted and lyophilized to less than $1 \mathrm{~mL}$ with procedures established at the Department of Limnology. The samples had been spiked with $0.5 \mathrm{~mL}$ phosporic acid $\mathrm{H}_{3} \mathrm{PO}_{4}$ directly after melting, which was concentrated up by the lyophilization. The resultant solution was essentially concentrated phosporic acid, which could not be further evaporated due to its low vapor pressure. Therefore, our usual

\footnotetext{
${ }^{1}$ University of Vienna, Faculty of Physics, VERA Laboratory, Währinger Straße 17, 1090 Vienna, Austria.

${ }^{2}$ Corresponding author. Email: peter.steier@univie.ac.at.

${ }^{3}$ University of Vienna, Faculty of Life Sciences, Department of Limnology, Althanstraße 14, 1090 Vienna, Austria.

${ }^{4}$ EBG MedAustron GmbH, Marie Curie-Straße 5, 2700 Wiener Neustadt, Austria.
} 


\section{P Steier et al.}

procedure of lyophilization followed by high-temperature combustion of the dry residue was not applicable.

When searching for an alternative, we considered possibilities to carry out wet oxidation. Chemical oxidizers added to the sample (like $\mathrm{H}_{2} \mathrm{O}_{2}, \mathrm{~K}_{2} \mathrm{~S}_{2} \mathrm{O}_{8}$, or $\mathrm{K}_{2} \mathrm{Cr}_{2} \mathrm{O}_{7}$ ) always impose the risk of contamination, either by extraneous carbon contents of the reagent itself, or from the laboratory environment when the apparatus is open for introduction. Additionally, these aggressive reagents might attack the stainless steel tubing of the sample processing line, the Viton ${ }^{\circledR}$ gaskets of the valves, and the vacuum pumps. Finally, traces of oxidizers also have the potential to passivate the iron catalyst required for the graphitization reaction (see below).

All of these potential complications can be avoided (or alleviated) by oxidation with ultraviolet (UV) light. UV radiation can penetrate into the sealed quartz vials, which excludes the possibility to introduce additional carbon contamination into the sample. Therefore, we think that our extensive studies on the carbon contamination of the lyophilization/combustion procedure carried out for human neuronal DNA samples (Bergmann et al. 2012) are also valid for UV oxidation, while a method based on oxidizing reagents would raise the demand for comprehensive additional investigations. Additionally, the UV oxidation mechanism is based on chemical radicals formed as intermediate reaction products, which disappear relatively quickly when the irradiation is switched off. Therefore, we consider it less likely that they cause damage to the equipment or degrade the catalyst.

Photochemical oxidation is not a new method for ${ }^{14} \mathrm{C}$ determination. It was developed and described beginning in the 1960s as a way to oxidize dissolved organic carbon (DOC) from seawater and freshwater samples (Williams et al. 1969). The advent of AMS allowed to reduce the water sample size for ocean water significantly (Williams and Druffel 1987; Beaupré et al. 2007; Griffin et al. 2010). UV oxidation was also employed for DOC extraction from meltwater from glacier ice by May et al. (2013). In these works, an UV lamp was applied to at least several $100 \mathrm{~g}$ of water without any preconcentration. The sample was irradiated as long as necessary and the $\mathrm{CO}_{2}$ was constantly extracted by bubble degassing.

Compared to these large-volume samples, in our case of preconcentrated samples of $\sim 1 \mathrm{~mL}$ a lower total UV flux is sufficient to oxidize the smaller volume. Thinner tube walls and a shorter path length inside the sample will reduce losses by absorption and self-absorption. Considerable experience exists on the photochemical quantification of DOC without ${ }^{14} \mathrm{C}$ measurement. Preunkert et al. (2011) use a similar setup as Beaupré et al. (2007) and May et al. (2013), while most other setups are based on an irradiation coil wound around a UV lamp (e.g. Collins and Williams 1977; Tue-Ngeun et al. 2005). In most cases, substances facilitating the oxidation or oxidizers are added to the sample. Sterilization of water and wastewater treatment are a widespread application of UV oxidation of organic matter.

Mercury discharge lamps are the most commonly used UV source. The emission spectrum of mercury is rich in UV lines, with the strongest at $250 \mathrm{~nm}$. Additionally, there are a number of lines below $200 \mathrm{~nm}$, preeminently at $185 \mathrm{~nm}$. While the $185-\mathrm{nm}$ line has several percent of the intensity of the 250-nm line in the ideal spectrum, the emission conditions and especially the glass walls modulate the spectrum significantly. Mercury discharge lamps are produced in several configurations, and categorized based on the mercury pressure at which the discharge takes place. Low-pressure UV lamps are essentially identical to those used for room lighting, but have a UV transparent enclosure and lack a fluorescent. Typically, the power per length is about $30 \mathrm{~W} / \mathrm{m}$, of which a few percent are hard UV with a wavelength below $240 \mathrm{~nm}$. Higher luminance is achieved with medium-pressure lamps, which have a typical length of $10 \mathrm{~cm}$, but an electrical power consumption of $100 \mathrm{~W}$ or more. 
High-pressure lamps operate also in the $100-\mathrm{W}$ range, but have a length of only 2 to $4 \mathrm{~cm}$. While they were produced in large number in the past for skin tanning and health treatment, they seem to have disappeared from the market recently due to their extremely high UV intensity in the close-up range, which can cause severe burns of the skin within seconds.

The mechanisms leading to oxidation of organic matter by UV light are discussed by Golimowski and Golimowska (1996) and Vig (1985). Soft UV (above $240 \mathrm{~nm}$ ) acts via the formation of excited (singlet) $\mathrm{O}_{2}{ }^{*}$ only if oxidizers or sensitizers (e.g. humic acids) are present in the sample. Therefore, only hard UV (below $240 \mathrm{~nm}$ ) is expected to be effective for our purpose. In the presence of oxygen, hard UV produces ozone $\mathrm{O}_{3}$ via the reactions

$$
\mathrm{O}_{2}+h v \rightarrow 2 \mathrm{O}, \mathrm{O}+\mathrm{O}_{2} \rightarrow \mathrm{O}_{3}
$$

In darkness and at room temperature, ozone is moderately stable. However, when irradiated with $200-300 \mathrm{~nm}$ light it decomposes rapidly via

$$
\mathrm{O}_{3}+h v \rightarrow \mathrm{O}+\mathrm{O}_{2}, \mathrm{O}+\mathrm{O}_{3} \rightarrow \mathrm{O}_{2}{ }^{*}+\mathrm{O}_{2}
$$

where $\mathrm{O}_{2}{ }^{*}$ represents excited oxygen molecules. The intermediate product atomic oxygen $\mathrm{O}$ of both the formation and destruction processes is a very strong oxidizing agent. Vig (1985) reports that even polytetrafluoroethylene (PTFE) is attacked by hard UV irradiation at extended exposure.

In aqueous solutions, the ozone serves as an intermediate stage for the production of the hydroxyl radical $\mathrm{OH} \bullet$, e.g. via

$$
\mathrm{O}_{3}+\mathrm{H}_{2} \mathrm{O}+h v \rightarrow \mathrm{H}_{2} \mathrm{O}_{2}+\mathrm{O}_{2}, \mathrm{H}_{2} \mathrm{O}_{2}+h v \rightarrow 2 \mathrm{OH} \bullet
$$

The hydroxyl $\mathrm{OH} \bullet$ radical is a non-specific oxidant that can decompose most organic compounds.

\section{METHOD}

Quartz glass is transparent for ultraviolet light, but the transmittance depends strongly on the purity. "Ozone producing" commercial lamps for hard UV are usually prepared from synthetic quartz, which at a thickness of $1 \mathrm{~mm}$ has about $90 \%$ transmittance for the $185 \mathrm{~nm}$ line. However, we were not able to obtain a reasonably small batch of synthetic quartz for our work, so we used our standard combustion vials made from natural quartz grade GE214 that has a transmittance of around $60 \%$. Quartz for soft-UV lamps is usually doped to block the 185-nm line completely.

Figure 1 shows a schematic of the irradiation vial containing the sample. The quartz vial with a length of $200 \mathrm{~mm}$, an outer diameter of $6 \mathrm{~mm}$ and a wall thickness of $1 \mathrm{~mm}$ is connected via a perfluoroalkoxy (PFA) ferrule to a modified Swagelok ${ }^{\mathrm{TM}}$ plug valve. The original metal plug with Viton gaskets seemed to introduce significant contamination in some cases. Beaupré et al. (2007) report a similar observation, and solved the problem by fitting solid glass rings around the circumference of the glass tubing (known as "marias"), which act to dissipate energy propagated through the tubing. We decided to replace the original plug with a PTFE cylinder without an O-ring. Thus, while oxidation takes place, only quartz, stainless steel, PFA, and PTFE are in contact with the sample.

The sample in solution is transferred with a pipette to the bottom of the vial, before the valve is attached and the head volume is replaced by pure oxygen. Presently, this step requires to freeze the sample, because vapor bubbles forming in the liquid phase would push the sample into the vacuum pump. However, the freezing bears the risk of losing the sample by breakage of the quartz vial due to the expansion of water ice. The vial has to be submerged into liquid nitrogen very slowly, to make 


\section{P Steier et al.}

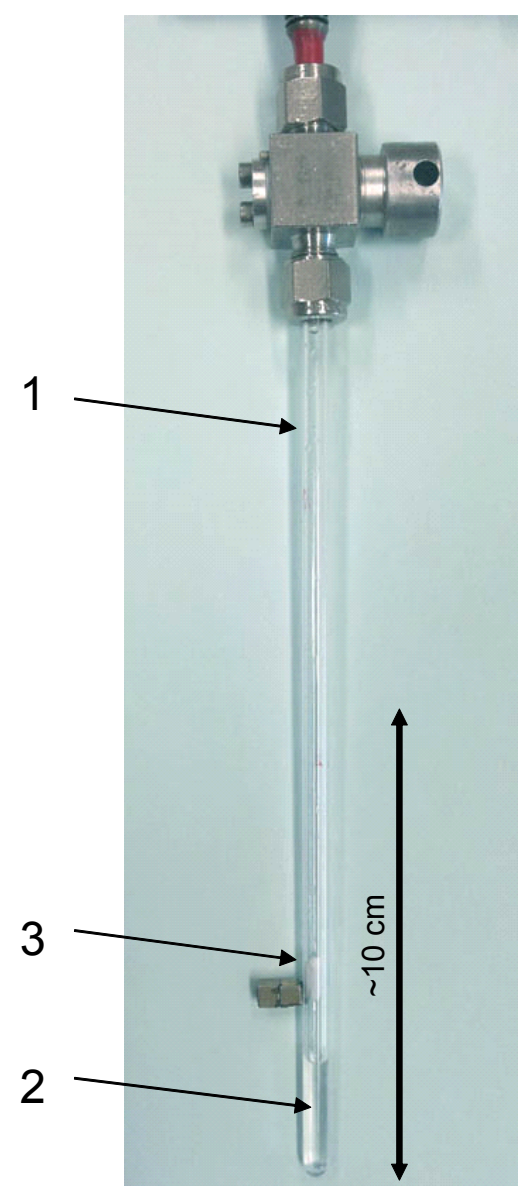

Figure 1 The irradiation vial made of quartz (1) with the sample in solution (2). A PTFE-coated magnetic swivel stick inside the vial is held and agitated inside the vial with a magnet from the outside.

sure that freezing progresses slowly from the bottom to the top. A magnetic swivel stick with PTFE coating is placed inside the vial to allow stirring of the sample from the outside with a magnet. This is done intermittently with UV irradiation, to introduce oxygen and ozone into the solution, while releasing the $\mathrm{CO}_{2}$ produced. To avoid possible disintegration of PTFE (Vig 1985), the swivel is lifted out of the irradiation zone before UV light is switched on.

The whole sample preparation procedure including UV oxidation can be carried out in the lyophilization/combustion/graphitization apparatus developed at VERA for small samples without significant modifications. This setup can process samples as little as $3 \mu \mathrm{g}$ carbon (Bergmann et al. $2012)$ with very low background $(0.08 \pm 0.06 \mu \mathrm{g} \mathrm{C})$. Sample $\mathrm{CO}_{2}$ is reduced to graphite by means of an iron catalyst (Vogel et al. 1984) following the established procedures described in Liebl et al. (2010). To make the handling of such small amounts of produced graphite possible, the iron catalyst is pressed in a small holder made from copper (inner diameter $1 \mathrm{~mm}, 1 \mathrm{~mm}$ deep). This sample holder is inserted as a whole into the graphitization reactor, and later mounted into the sample magazine for the AMS carrying the deposited carbon. The iron is pretreated by baking in $\mathrm{H}_{2}$ gas at $915^{\circ} \mathrm{C}$ for $2 \mathrm{hr}$ directly before sample preparation. The quality of the catalyst surfaces seems to be especially important for ultra-small carbon samples. Traces of oxidizing agents reaching the pretreated iron could easily lead to degradation, resulting in slow or incomplete reduction. 
Figure 2 shows the layout of 1 unit. The setup is based on exceptionally small graphitization reactors of only $0.7 \mathrm{~cm}^{3}$ volume. This is achieved by machining the whole reactor assembly from 1 piece of stainless steel, including valve, cold trap, and Swagelok connectors for the quartz vial with the catalyst and the pressure sensor. For the valve, an original Swagelok plug with Viton gasket is used, which was verified not to introduce significant contamination. For each of the 9 reactors in the apparatus, there is a separate sample treatment vial connected by standard Swagelok components. PFA ferrules are used as gaskets for the connections. Inside this vial, lyophilization, combustion at high temperatures, and, for the present work, oxidation with UV light takes place. The fact that all these steps including the following graphitization are carried out in the same, hermetically sealed assembly helped significantly to reduce the carbon background. Nine samples can be processed in parallel.

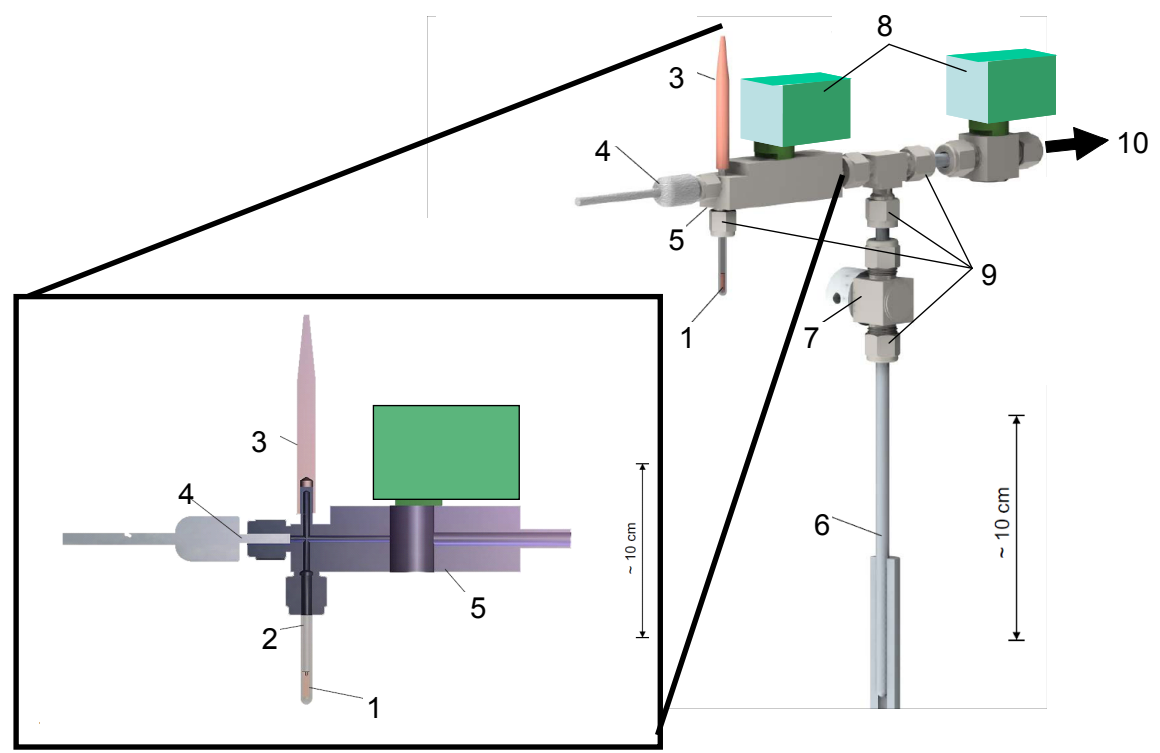

Figure 2 Layout of the lyophilization/oxidation/graphitization setup for small samples at VERA: (1) copper holder with iron catalyst; (2) heated quartz vial of graphitization reactor; (3) cold finger of reactor; (4) pressure sensor; (5) reactor body; (6) quartz vial for lyophilization/combustion or UV oxidation; (7) modified Swagelok valve with PTFE plug; (8) servo motors for valves; (9) Swagelok fittings with PFA ferrules; (10) to pump.

\section{First Prototype of the UV Irradiation Unit}

A first proof of principle was carried out with a provisional prototype of the irradiation device. Figure 3 shows a schematic of the irradiation geometry, which is similar to that described by Beaupré et al. (2007) but on a significantly smaller scale ( 1:5). As an UV source, we used a high-pressure mercury vapor lamp taken from a skin tanning set (Sonnenkind, model Anita) from the 1970s, with unknown spectrum. However, it revealed its UV-producing nature by a strong smell of ozone. The lamp was operated at a power of $100 \mathrm{~W}$ and the discharge had an effective length of $4 \mathrm{~cm}$ and a diameter of several $\mathrm{mm}$. The lamp and the sample were placed in the focal lines of an elliptical reflector of polished stainless steel (Figure 3). Stainless steel has a reflectivity of about $20 \%$ for the 185-nm line, and is not degraded by UV radiation (Vig 1993). To avoid overheating the sample, a quartz liner was added around the sample vial, through which nitrogen from a bottle was blown for cooling $(\sim 1 \mathrm{~L} / \mathrm{min})$. The apparatus was mounted in a light-tight steel box. We roughly estimate an 


\section{P Steier et al.}

irradiance of $20 \mathrm{~mW} / \mathrm{cm}^{2}$ in the spectral range below $200 \mathrm{~nm}$ inside the sample, similar to what we estimate for the device presented in Beaupré et al. (2007), based on the published information.

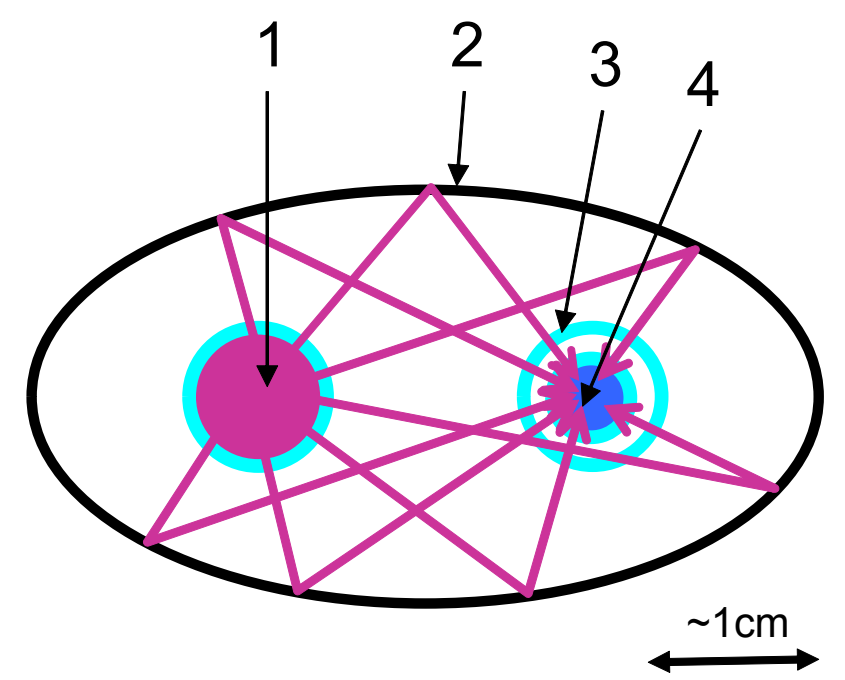

Figure 3 Irradiation geometry of the prototype: (1) high-pressure mercury discharge lamp; (2) stainless steel reflector; (3) quartz liner for sample cooling with $\mathrm{N}_{2}$ flow; (4) dissolved sample in quartz vial.

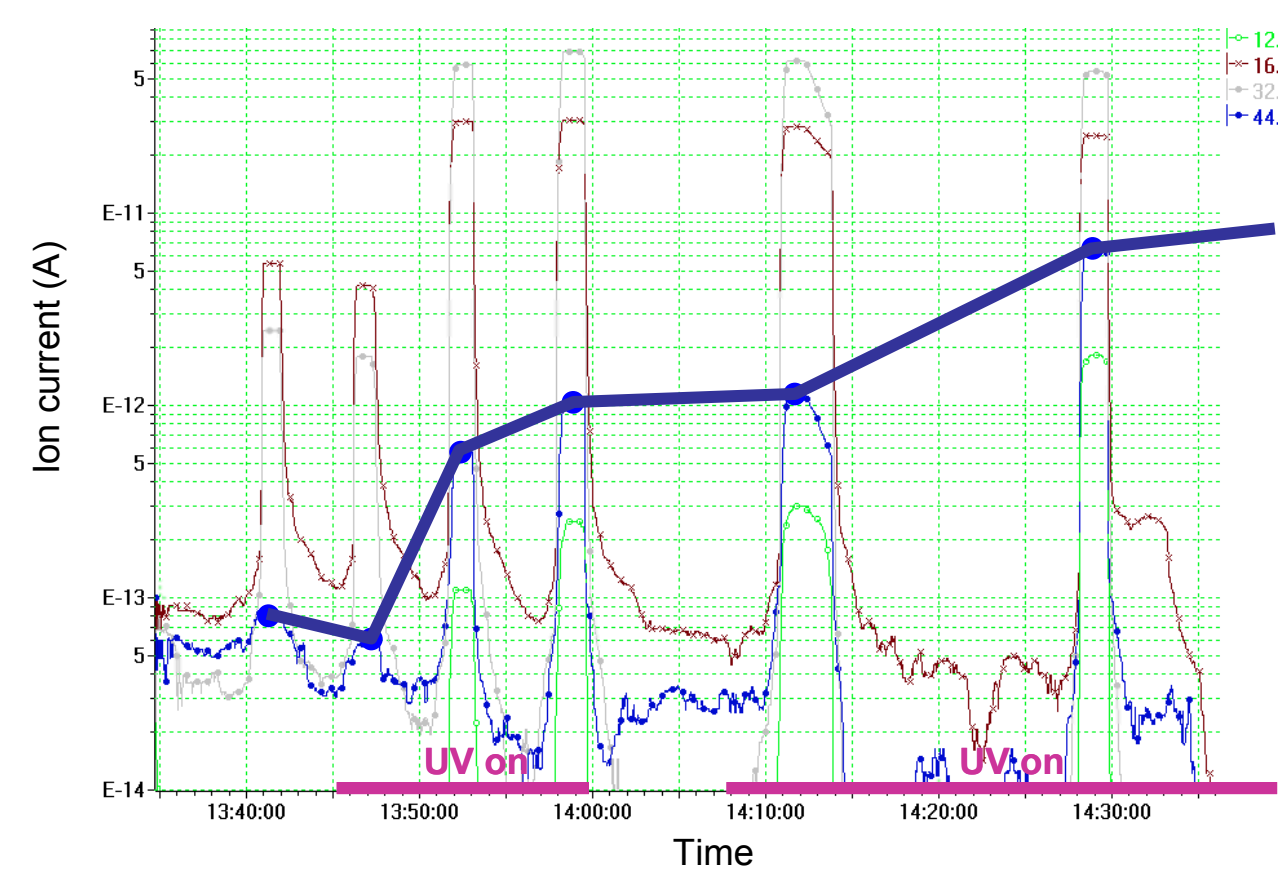

Figure 4 Detection of $\mathrm{CO}_{2}$ produced by UV irradiation with an RGA. Shown are the ion currents for mass 12 (green), 16 (brown), 32 (gray), and 44 (blue). The peaks correspond to time intervals when gas from the vial is sampled and bled into the RGA. The peaks of mass 44 (corresponding to $\mathrm{CO}_{2}$ ) are connected by the thick blue eye guide. Intervals with UV irradiation are marked on the time axes. 
To study the production of $\mathrm{CO}_{2}$, the composition of the gas inside the vial was sampled repeatedly during irradiation, and the composition was measured with a residual gas analyzer (RGA). Figure 4 shows the time development for an artificial sample of glucose with $20 \mu \mathrm{g}$ carbon dissolved in $500 \mathrm{~mL}$ of water. Since the sampling volume and the setting of the metering valve bleeding into the RGA were left constant, the ion current of mass $44 \mathrm{amu}$ should be proportional to the partial pressure of $\mathrm{CO}_{2}$. Indeed, a rise of mass 44 was observed when the UV light was switched on. Also the breakup product ${ }^{12} \mathrm{C}_{\text {of }} \mathrm{CO}_{2}$ is visible (this breakup takes place inside the ion source of the RGA, not in the UV irradiation reactor). After $1 \mathrm{hr}$, the rise in pressure slowed down and the oxidation was apparently complete.

\section{FINAL SETUP}

Based on the experience with the prototype, a setup for the parallel irradiation of 9 samples was built. Unfortunately, we did not find additional ozone-producing high-pressure mercury lamps. Old examples that we obtained from various sources all turned out to use doped quartz. Since 9 lamps in parallel would be needed, medium-pressure mercury lamps (or similar types produced mainly for research and engineering) would have exceeded our budget constraints. Therefore, we decided to resort to low-pressure mercury lamps. These lamps can be operated with standard ballasts for room lighting, thus also the need for expensive power supplies is omitted. Any reduction in UV irradiance has to be compensated by longer irradiation times.

The lower luminance of the lamps requires a completely different design than that used for the prototype. To apply the highest UV dose possible, the solid angle seen by the sample should be completely covered by UV-emitting surfaces. We approach this goal by using $4 \mathrm{U}$-shaped lamps (SterL-Ray ${ }^{\circledR}$, Type G30T6VH/U) of $35 \mathrm{~cm}$ length (Figure 5). Two lamps (i.e. 4 UV-emitting tubes) are placed on both sides of the 9 sample vials, which are mounted at a spacing of $32 \mathrm{~mm}$ perpendicular to the lamps. Each lamp has an electrical power of $11 \mathrm{~W}$. From the ozone production quoted, one can estimate an intensity of approximately $2 \mathrm{~W}$ in the region below $200 \mathrm{~nm}$, corresponding to an irradiance of about $5 \mathrm{~mW} / \mathrm{cm}^{2}$ at the position of the sample vial. This is about 5 times lower than for our prototype and the device presented in Beaupré et al. (2007). The lamp assembly is mounted inside a UV-tight housing made of stainless steel; small holes with narrow steel tubes attached allow to insert the sample vials. To minimize production of ozone outside the sample vials and exposure of the operator, nitrogen is flowed through the housing at a rate of $300 \mathrm{~mL} / \mathrm{min}$. The lower electrical power distributed over a larger surface strongly reduces the demand for cooling; however, cooling is provided by a heat exchanger made of a double-sided aluminum heat sink mounted in the wall of the housing, ventilated with fans from inside and outside. During irradiation, the samples reach a temperature of about $60^{\circ} \mathrm{C}$, as measured in a dummy sample vial filled with water.

The samples are irradiated for $2 \mathrm{hr}$, with breaks every $\sim 10 \mathrm{~min}$, when they are lifted out of the irradiation unit and stirred. During this step, small bubbles of $\mathrm{CO}_{2}$ are usually visible. The operators of the unit wear eye protection whenever the UV light is on. The laboratory has a forced ventilation that prevents accumulation of ozone in the laboratory air.

Before use, the quartz vials were cleaned with hot $\left(100^{\circ} \mathrm{C}\right) 8 \mathrm{M} \mathrm{HCl}$ for $1 \mathrm{hr}$, rinsed with $18 \Omega \mathrm{M}$ water and acetone, and baked at $900{ }^{\circ} \mathrm{C}$ for $4 \mathrm{hr}$. The PTFE-covered magnetic steerer, the valves and all used tools were cleaned with $\mathrm{NH}_{3}(25 \%)$ in an ultrasonic bath and rinsed with $18 \Omega \mathrm{M}$ water. Samples were handled inside a laminar flow hood (class 100) and dust was blown off from the tools with nitrogen inside the hood. 


\section{P Steier et al.}

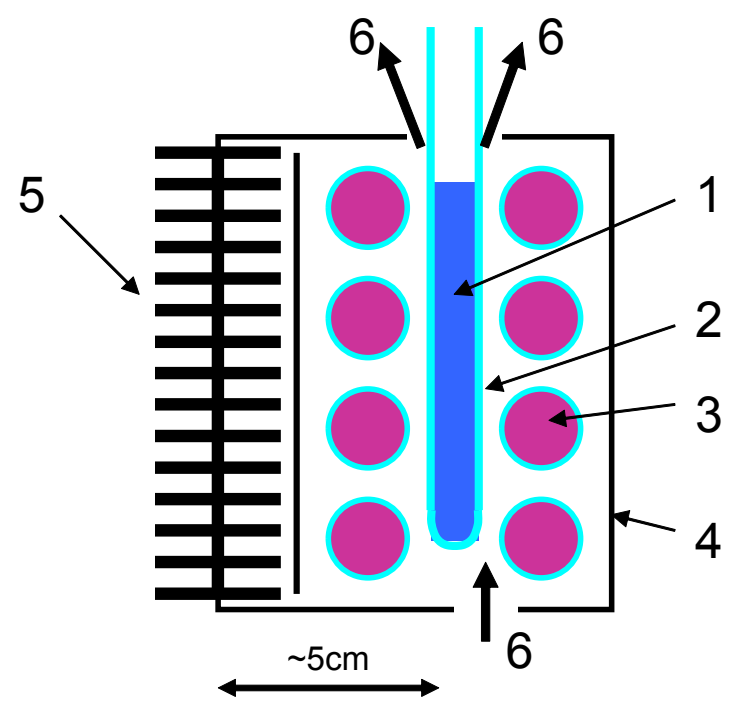

Figure 5 Irradiation geometry of the final setup: (1) sample in solution; (2) quartz vial; (3) low-pressure mercury discharge lamp; (4) stainless steel housing; (5) heat exchanger (aluminum); (6) nitrogen flow.

\section{BENCHMARK MEASUREMENTS AND FIRST RESULTS}

So far, a limited number of systematic measurements have been carried out. Table 1 shows the results obtained on (nominally) carbon-free samples. We used analytical-grade $\mathrm{H}_{3} \mathrm{PO}_{4}$ and GIBCO UltraPure ${ }^{\mathrm{TM}}$ water without pretreatment. The total carbon mass extracted was determined by transferring the produced $\mathrm{CO}_{2}$ into the graphitization reactors, where the amount is determined with the pressure sensor. The precision of the measurement is better than $0.2 \mu \mathrm{g}$ carbon. Despite the significant scatter among the results and their limited number, the 2 samples of $\mathrm{H}_{2} \mathrm{O}+\mathrm{H}_{3} \mathrm{PO}_{4}$ suggest a background of $1.1 \pm 0.7 \mu \mathrm{g}$ carbon (average and standard deviation of the 2 values). The high value for the empty tube $(1.7 \mu \mathrm{g} \mathrm{C})$ may indicate that the background does not only originate from the reagents. However, more investigations are needed to clarify this issue.

Table 1 Results for carbon free "blank" measurements.

\begin{tabular}{ll}
\hline Material & $\mu$ g carbon detected \\
\hline $\mathrm{H}_{2} \mathrm{O}$ & 0.3 \\
$\mathrm{H}_{2} \mathrm{O}$ & 0.3 \\
$\mathrm{H}_{2} \mathrm{O}+\mathrm{H}_{3} \mathrm{PO}_{4}$ & 0.6 \\
$\mathrm{H}_{2} \mathrm{O}+\mathrm{H}_{3} \mathrm{PO}_{4}$ & 1.6 \\
Empty vial & 1.7 \\
\hline
\end{tabular}

To obtain an idea on the extraction yield of the procedure, we prepared a first set of samples from different materials (Table 2). The solid and chemically inert materials PTFE and graphite show minimal $\mathrm{CO}_{2}$ production. Similarly, no $\mathrm{CO}_{2}$ is produced for lipids (triglycerides) irradiated without the addition of water. Wet cellulose (IAEA C-3 with 1 drop of water) releases a small amount of $\mathrm{CO}_{2}$; for the completely dissolved materials sucrose and gelatin, half of the material is extracted as $\mathrm{CO}_{2}$. Completely dissolved DNA, which is an exceptionally UV-resistant molecule under suitable conditions, is digested to $\mathrm{CO}_{2}$ with $23 \%$ yield. 
New UV Oxidation Setup for Small ${ }^{14}$ C Samples in Solution

Table 2 Extraction yield for different materials.

\begin{tabular}{llcc}
\hline Materials & $\mu \mathrm{g} \mathrm{C}$ used & $\mu \mathrm{g} \mathrm{C}$ extracted & Yield \\
\hline Commercial PTFE (small piece) & 620 & 0.4 & $0 \%$ \\
Lipids (triglycerides) extracted from foodstuff lard & 571 & 0.6 & $0 \%$ \\
High purity graphite (small piece) & 170 & 0.4 & $0 \%$ \\
IAEA C-3 Cellulose (wet) & 67 & 5.7 & $9 \%$ \\
IAEA C-6 Sucrose (solution) & 51 & 26.3 & $52 \%$ \\
Foodstuff gelatin (solution) & 34 & 21.1 & $63 \%$ \\
Invitrogen $^{\mathrm{TM}}$ Herring Sperm DNA (solution) & 45 & 10.2 & $23 \%$ \\
\hline
\end{tabular}

For the glacier samples prepared for Singer et al. (2012), we do not discuss the results and the biogeological interpretation in the present manuscript. However, we report a methodical benchmark: when comparing the amount of $\mathrm{CO}_{2}$ extracted and measured in the graphitization reactor to the independent DOC measurement, an extraction yield of $(64 \pm 17) \%$ was achieved by UV oxidation.

\section{CONCLUSIONS}

Ultraviolet light provides another method for the oxidation of samples for ${ }^{14} \mathrm{C}$ measurements, and we have especially investigated small samples up to $50 \mu \mathrm{g}$ carbon in solution. Samples in solution can be treated without lyophilization, which significantly simplifies the procedures. Low-pressure mercury vapor lamps are sufficient to treat such samples for many applications. Within $2 \mathrm{hr}$ of irradiation, a yield above $50 \%$ is possible, which is sufficient for samples with homogenous ${ }^{14} \mathrm{C}$ content. However, complete oxidation is generally needed to characterize the mixture of organic compounds in a heterogeneous, environmental sample. Considering the lower irradiance in our device compared to that described in Beaupré et al. (2007), irradiation times of up to $20 \mathrm{hr}$ would be required. However, the capability to treat 9 samples in parallel may compensate for the longer measurement duration. The new method is basically ready for routine application despite the fact that more systematic investigations are required to minimize the blank level and maximize yield.

\section{ACKNOWLEDGMENT}

We are thankful to the anonymous reviewer for her/his critical comments, which helped to improve the manuscript significantly.

\section{REFERENCES}

Beaupré SR, Druffel ERM, Griffin S. 2007. A low-blank photochemical extraction system for concentration and isotopic analyses of marine dissolved organic carbon. Limnology and Oceanography: Methods 5:174 84.

Bergmann O, Liebl J, Bernard S, Alkass K, Yeung MSY, Steier P, Kutschera W, Johnson L, Landén M, Druid H, Spalding KL, Frisén J. 2012. The age of olfactory bulb neurons in humans. Neuron 74:634-9.

Collins KJ, Williams PJLB. 1977. An automated photochemical method for the determination of dissolved organic carbon in sea and estuarine waters. Marine Chemistry 5:123-41.

Golimowski J, Golimowska K. 1996. UV-photooxidation as pretreatment step in inorganic analysis of environmental samples. Analytica Chimica Acta 325:11133.
Griffin S, Beaupré SR, Druffel ERM. 2010. An alternate method of diluting dissolved organic carbon seawater samples for ${ }^{14} \mathrm{C}$ analysis. Radiocarbon 52(3):1224-9.

Liebl J, Avalos Ortiz R, Golser R, Handle F, Kutschera W, Steier P, Wild EM. 2010. Studies on the preparation of small ${ }^{14} \mathrm{C}$ samples with an RGA and ${ }^{13} \mathrm{C}$-enriched material. Radiocarbon 52(3):1394-404.

May B, Wagenbach D, Hoffmann H, Legrand M, Preunkert S, Steier P. 2013. Constraints on the major sources of dissolved organic carbon in Alpine ice cores from radiocarbon analysis over the bomb-peak period. Journal of Geophysical Research: Atmospheres 118(8):3319-27.

Preunkert S, Legrand M, Stricker P, Bulat S, Alekhina I, Petit JR, Hoffmann H, May B, Jourdain B. 2011. Quantification of dissolved organic carbon at very low levels in natural ice samples by a UV-induced oxida- 


\section{P Steier et al.}

tion method. Environmental Science \& Technology 45(2):673-8.

Singer GA, Fasching C, Wilhelm L, Niggemann J, Steier P, Dittmar T, Battin TJ. 2012. Biogeochemically diverse organic matter in Alpine glaciers and its downstream fate. Nature Geoscience 5:710-4.

Tue-Ngeun O, Sandford RC, Jakmunee J, Grudpan K, McKelvie ID, Worsfold PJ. 2005. Determination of dissolved inorganic carbon (DIC) and dissolved organic carbon (DOC) in freshwaters by sequential injection spectrophotometry with on-line UV photo-oxidation. Analytica Chimica Acta 554:17-24.

Vig JR. 1985. UV/ozone cleaning of surfaces. Journal of Vacuum Science and Technology A 3:1027-34.
Vig JR. 1993. Ultraviolet-ozone cleaning of semiconductor surfaces. In: Kern W, editor. Handbook of Semiconductor Wafer Cleaning Technology. Park Ridge: Noyes Publications. p 6-273.

Vogel JS, Southon JR, Nelson DE, Brown TA. 1984. Performance of catalytically condensed carbon for use in accelerator mass spectrometry. Nuclear Instruments and Methods in Physics Research B 5(2):289-93.

Williams PM, Druffel ERM. 1987. Radiocarbon in dissolved organic carbon in the central North Pacific Ocean. Nature 330(6145):246-8.

Williams PM, Oeschger H, Kinney P. 1969. Natural radiocarbon activity of dissolved organic carbon in North-east Pacific Ocean. Nature 224(5216):256-8. 